Morrison-Love, D. (2017) Towards a transformative epistemology of technology education. Journal of Philosophy of Education, 51(1), pp. 23-37. (doi:10.1111/1467-9752.12226)

There may be differences between this version and the published version. You are advised to consult the publisher's version if you wish to cite from it.

This is the peer-reviewed version of the following article: MorrisonLove, D. (2017) Towards a transformative epistemology of technology education. Journal of Philosophy of Education, 51(1), pp. 23-37, which has been published in final form at 10.1111/1467-9752.12226. This article may be used for non-commercial purposes in accordance with Wiley Terms and Conditions for Self-Archiving.

http://eprints.gla.ac.uk/112408/

Deposited on 15 July 2016

Enlighten - Research publications by members of the University of Glasgow http://eprints.gla.ac.uk 
This is a pre-publication version of a paper accepted for publication in the Journal of Philosophy of Education.

Please feel free to get in contact with the author:

Dr David Morrison-Love

School of Education, University of Glasgow

david.morrison-love@glasgow.ac.uk 


\title{
TITLE: $\quad$ TOWARDS A TRANSFORMATIVE EPISTEMOLOGY OF TECHNOLOGY EDUCATION
}

\begin{abstract}
Technology Education offers an authentic and invaluable range of skills, knowledge, capabilities, contexts and ways of thinking for learners in the $21^{\text {st }}$ century. However, it is recognised to occupy a comparatively less defined and more fragile curricular position than associated, but longer established, subjects such as Mathematics and Science. While recognising that no single factor lies behind such a condition, this paper draws upon thinking in the philosophy of technology, technology education and the ontology of artefacts to argue that transformation may be considered as a epistemic source for technology in a similar way to 'proof' within Mathematics and 'interpretation' within Science. Encapsulating technology's intimate relationship with materials, it is ultimately argued that the transformation of a technical artefact from an ill-defined into a well-defined ontological state constitutes a prime source of technological knowledge for pupils. Moreover, it provides an alternative route into further consideration about the nature of the domain, epistemology and curricular identity of the subject.
\end{abstract}

Keywords: Technology Education, Transformation, Epistemology, Ontology

\section{PHILOSOPHY OF TECHNOLOGY EDUCATION}

With technology education as a curricular area developing from industrial roots only at the turn of the last century, the philosophy of technology education is a small and comparatively new field of inquiry. Despite such infancy, and closely shaped by thinking in the philosophy of technology, the field has cultivated a number of significant shifts over the last two decades, 
currently characterised on four prominent but interrelated fronts. In no order of significant, the first front is the modes of, and ways in which, technology manifests itself including as object, knowledge, activity and volition (Mitcham, 1994; Frey, 1989; Custer, 1995; Frederik et al, 2010). This work has implications for the role of artefacts, systems, conceiving and making in technology classrooms. The second front focusses on the relationship between technology and science in which historically accepted assumptions have been challenged and contested by a number of authors (Layton, 1993; Gardner, 1994; Barlex \& Pitt, 2000). Currently, it is widely accepted that technology occupies a far more complex and substantive role than applied science, but also that there is a lack of consensus on subsequent emergent paradigms (de Vries, 1996). The renewed prominence of the STEM paradigm has refocussed attention on the importance of this relationship (Williams, 2011). The third front involves inquiry into the nature of technological knowledge. The extent of current consensus suggests this to have conceptual, procedural and tacit elements (McCormick, 2006), that it is closely bound to practical activity and still much debated (Fleer, 2015). More specifically, some authors have suggested it can be identify in the form of maxims, laws, theories and rules (Vincenti, 1990; Ropohl, 1997). As noted by Norström (2011), many of these are qualitative, arising from practice and not the product of mathematical modelling or scientific verification (such as the relationship between drilling speeds and cutter diameter in steelwork). Notably, an overall epistemic framework has not been identified. Closely related to this, the fourth and final front is characterised by discourse exploring the extent to which technology can be defined and delimited more discretely as a domain or subject in its own right (Weatjin, 1993; Lewis, 2004; de Vries, 2011). A pivotal book by Williams et al (2015), mapping the current state and future of the field recognises, as Weatjin did over two decades previously, that technology education is still without a recognised epistemic basis and cites this as one of the major challenges still to be addressed. Notably, Jones et al (2013), following a similar review of the field also call for 
continued efforts to better define and clarify the field of technology education. Moreover, they argue that in the absence of an obvious structured domain, this must come from historical and philosophical perspectives that can appropriately inform on the subject area.

This paper invites renewed focus on consolidating a domain for technology education by offering a new perspective. Rather than attempting to further break down and epistemically map facets and entities of technological knowledge, this paper examines epistemic sources as an alternative means of distinguishing between subject domains. Ultimately, it is argued that whilst the epistemology of mathematics arises from the seeking of proof, and that of science from the interpretation of nature, the epistemology of technology arises from transformation.

\section{THE PROBLEMATIC EPISTEMOLOGY OF TECHNOLOGY}

In discussion of subjects for study, Technology is regularly allied with Science, Engineering and Mathematics; a group collectively denoted by the 'STEM' acronym. On a prima facie level, this association appears logical and supported by a notable degree of interrelatedness of content. It is futile, for instance, to deny that Science and Engineering make prolific use of mathematics and that Technology draws upon aspects of scientific thinking and so forth. It seems that, on this level at least, there is a fluid and transactional quality to the knowledge dimension of this alliance. That being said, it can be argued that the more deeply one seeks to reveal the epistemic nature of each, the more Technology is rendered the 'odd one out'. Before exemplifying this assertion with reference to Mathematics and Science, it is necessary to comment upon the relationship between Engineering and Technology. This author would regard the discipline of Engineering to typically rely upon greater quantitative-analytical content and be able to encompass conceptual development that is much further removed from immediate human utility than technology. Moreover, conceptual scale plays a role. An 
example of an engineering artefact could be a newly developed and more effective train carriage coupling. Here, the influences that shape development could conceivably have nothing to do with human interaction, though on a larger scale, the train as a whole could be seen as technological. This is similarly reflected in technology classrooms where some aspects of pupil activity could be characterised more specifically as engineering rather than technology. Analysis of the complexities of this beyond recognising the essential role of human utility in technology would add little to the value of this argument. Further to this, any reference made to technology and the classroom setting is in reference to the curricular subjects of technology rather than the generic classroom use of Technology in sense of things such as ICT. So what of the odd one out? The nature and sources of the body of knowledge associated with Mathematics and Science will be examined as a basis against which to characterise the nature and source of knowledge for Technology.

The most broadly accepted foundationalist archetype for mathematical epistemology is declared by Buldt et al (2008) to rest upon the requirement of mathematical proof, on the basis that "mathematical theorems are a priori truths about acausal, non-spatio-temporal objects" (p.310). One way in which the authors challenge this rests in the fact it cannot sustain those instances where proofs are contested. Indeed, the precept they question is one of certainty and absolutes. Towards the other end of the continuum, Ormwell (1993) discusses the radical social-constructivist viewpoint that sees Mathematics as a form of social culture. This, by contrast, explicitly denies the possibility of absolutes and certainty. In some senses, the fallibility at very high levels of mathematics can be seen to be functionally congruent with the Cambium layer of a tree; proportionally the smallest region, but that which is ultimately responsible for new growth. Despite such fallibility, and subjective extremes in culturallygrounded explanations of Mathematics, the body of mathematical knowledge with which pupils commonly engage to develop their own understanding is characteristically objective. It 
is highly structured, with explicit relationships, rules, operators and epistemic organisers. In this context, Mathematics is ostensibly objective, exhibiting a semiotic and temporal constancy that is both valued and serves to strengthen its curricular identity. Though epistemologically different, notable similarities are observed in the case of Science.

Whilst Mathematical knowledge may stem from the seeking of proof, Driver et al (1994) argue that scientific knowledge arises through interpreting nature. Though they recognise that there is no single way to adequately describe the nature of science, they do argue that scientific knowledge is "both symbolic in nature and socially negotiated" (p.5). They describe how scientific knowledge is collectively generated, socially constructed and validated. Moreover, they note that this gives rise to a body of empirical knowledge with ontological entities (such as atoms and chromosomes), relationships and organising concepts that, together, function to symbolically interpret nature. As with Mathematics, the resultant body of core scientific knowledge with which pupils are likely to engage can be seen to share a similar degree of objectivity and temporal constancy. It would be unlikely, for example, that pupils could meaningfully study Chemistry without learning about reactions or atoms, just as it would be for pupils in Mathematics to disregard multiplication. In these cases, the form taken by the holistic epistemology is shaped, and predicted, by what is known of the nature of constituent ontological entities and the relationships and dependencies between them.

From the above discussion, it could ultimately be argue that whilst Mathematical and Scientific domains differ in content and their respective epistemic drives for proof and interpretation, they nevertheless share a structure and degree of objectivity in the natures thereof. In contrast, Waetjen (1993) argues that this is not something extended to Technology. Significantly, he also sees such a domain as the source from which curricular content and knowledge is determined; something indeed reflected in the case of Mathematics and Science. He correctly argues that Technology Education in schools has not succeeded in establishing a similar 
domain of its own, previously noted by Jones et al (2013) as something true to this day. However, it will be proposed in this paper that where Mathematics is epistemically predicated upon 'Proof', and science upon 'Interpretation', Technology — especially for the purposes of Technology Education and classroom learning-could be better defined by locating its epistemic basis firmly in 'Transformation'. It can be argued that doing so achieves a number of desirable outcomes. Firstly, it allows a valuable range of existing thinking about the nature of technological knowledge and understanding to be synthesised and meaningfully tied together. Secondly, it provides a kernel from which can look to develop new approaches to and considerations about the validation of curricular knowledge and content at a range of levels. Thirdly, it provides a consistent mechanism through which the curricular identity and value of Technology Education may be better illuminated and ultimately understood.

\section{LOCATING A TRANSFORMATIVE EPISTEMOLOGY IN THE PHILOSOPHOCAL}

\section{LANDSCAPE}

Continuing philosophical discussions reveal a range of ontological distinctions and scales on which technology, and many dimensions of it, can be theorised (e.g. Pitt, 2000; Lawson, 2008; Heidegger, 1977; Mitcham, 1994). Though each constitutes an important contribution to our developing and changing understanding of technology, the inherent complexity and multifariousness are salient features giving rise to tensions within the task of crystallising a curricular identity and a structured intellectual domain. It is not unreasonable to argue that this is attributable to the multitude of ways and contexts in which technology is viewed, used and developed in social and cultural contexts; the associated values of groups and individuals, in addition to its aforementioned lack of epistemic clarity. It is hence prudent that this paper is 
appropriately anchored to specific locations within this landscape that afford meaningful contributions to be made to classroom-level Technology Education.

To achieve this, attention will initially be drawn to two areas of discourse that have informed this thinking. The first of these is the metaphorical paradigm of technology as an extension of human capability. In addition to viewing technology as 'normative', 'end-effect' and 'naturalistic', this is a fourth broad means of explaining technology set forth in a key paper by Kornwachs (1998). This conception of technology as human augmentation has its roots in the work of Kapp (1877) and is distinct from schools of thought in which technological metaphors are functions of linguistic analogy (e.g. Edge, 1974). It can, for example, be argued that the telephone is a piece of technology that enhances the user's ability to communicate over long distances; that a digital oscilloscope provides an Engineer with the capability of 'seeing' electrical waveforms; or that a hammer increases our physical ability to drive a nail into a piece of timber. Here, it is possible to revert to deterministic assertions about the nature of the relationship between the technology and the user. However, consideration of the complex roles of factors such as skill, mastery, expertise and intuition most often reveal the relationship to be one of inter-dependence and not meaningfully reducible in such a manner. Though the significance of this paradigm ultimately realised at a later stage, it is provisionally noted as offering a lens for understanding the use and development of technology as experienced by pupils in Technology Education; in other words, philosophically informing at the level of pupil praxis. Pupils often utilise technologies in a metaphorical and capacity-enhancing sense to both understand and create their own technical artefacts that are themselves, capacityenhancing. The second area for attention is the more contemporary shift in the level of philosophical analysis from broader societal level concepts, such as technological determinism - which explores the extent to which human volition is curtailed by the influence of technology (Pannabecker, 1991; Smith \& Marx, 1994, Padersen, 2001) - to that of the 
discrete technological artefact as noted by de Vries (2008). It is recognised that these more recent philosophical considerations of 'the artefact' again share an immediacy with the majority of pupils' own technological interactions that provides a profitable nexus for further considering epistemology in this context.

It is hence the metaphorical paradigm that helps conceptualise the common roles of technology in pupils' local and immediate activity, and the ontology of technological artefacts that discloses the nature of that which is produced as a result and its influence on production. As with many conceptualisations of this nature, there are limitations and boundaries to their applicability, though the sufficiency in this context is such that they will ultimately allow notions of volition, intention and purposeful creation to be embedded in what is understood of technically distinct artefacts.

\section{TECHNOLOGY AS OBJECT, PROCESS \& TRANSFORMATION}

Frey (1989) demonstrates (as do many others) that technology can be conceptualised in a range of ways including both as process and as object. Certainly, Technology in the form of objects is reflective of the conception pupils are most likely to draw from engagement with presentday technology subjects. Not only is the technology department typically seen as one that is home to a vast number of technical objects, a large part of the learning pupils undertake will involve interaction with and use of such objects. From pencils through to drills and thence computers, $\mathrm{CNC}$ machines and rapid prototyping, these vary in complexity but are employed by pupils in the metaphorical sense to facilitate the formation of technological solutions. It is notable that despite our occupation of an increasingly digital, technologically complex and 'high-tech' world, day-to-day technology remains firmly manifest in the form of man-made, material objects. It is the manipulation of materials that facilitates the existence of virtual and 
high-technology environments. In this sense, object and process cannot be mutually exclusive. Simpson's (2009) argument that "technological practice aims at solving the material problems of human life..." essentially ties together this notion of technology as object with the aforementioned conception of technology as process. Arguably, it is the this complex interaction with materials towards an improved state of material reality that helps define the technologist; though it is recognised that the term technologist can refer to a wide range of skill sets and contexts.

Prior reference to both pencils and rapid prototyping reflects the notion of technological advancement as captured and implicit in our currently held perceptions of low and high technology objects. This is the first (and most general) way in which technology is inextricably linked to transformation, albeit in a socio-historical sense. Philosophers such as Albert Borgmann reflect just such a sense in their examination of the societal effects of developmental transformation. Though from a sometimes differing philosophical perspective, Heidegger (1977) talks of the literal transformation of our world. Here, it is prudent to note that the remaining section of the above quote by Simpson's (ibid) reads: “...by increasing our power to transform the natural and social worlds." As well as tying such endeavour to material reality, it is hence extended and tied to the natural and social realities of interest to Borgmann, Heidegger and many others. In most cases, however, such shifts on a societal level are the cumulative result of numerous smaller-scale changes; perhaps in, inert alia, the technological practices previously alluded to by Simpson. In the context of pupils and classroom learning, a selection of other authors consolidate transformation on a smaller and more local level by revealing a number of more specific ways in which it is embodied within 'technical' artefacts, activity and practice.

On a fundamental and pragmatic level, Frey (1989) discusses technology as the transformation of materials in terms of their properties and production. This is very much concerned with 
man's manipulation of bulk mechanical and physical properties, dating back thousands of years, such that given materials perform to desired specifications and requirements when in service. At this level, it can be said that technology is closely associated with transforming materials, initially in and of themselves often with a view to further configurative transformation into some form of useful object. Kassels (2010) formalises this yet further by encapsulating the concept of embedded transformation within objects as one of a range of required conditions for those objects to be ontologically defined as 'technical'. Indeed, consideration of what constitutes technical and non-technical objects can be traced back to Aristotelian distinctions between the natural-internal and human-external forces of object formation. Problematically, notwithstanding the means by which objects are understood to be man-made, it does not necessarily follow that such objects can be considered 'technological'. Indeed, Aristotle's own example of a sculpture embodies often exquisitely, the skill, craft and techné brought to bear upon shaping the material by the sculptor-in many of the senses explored in the work of Sennett (2008). Though man-made, and perhaps of remarkable similarity to certain phases of skilled technological activity, this alone does not decree the sculpture to be a technical artefact. What is important here, however, is that different forms of transformation can still be identified at this level.

From a yet different analytical stance, and stemming from inquiry of a model of social activity, Lawson (2008) explicitly sets transformation within the context of technical activity and undertakes to consider the connections between, and associated ontological nature of, technical artefacts. Here, Lawson argues that technology is irreducibly social and posits an ontological account of artefacts that rests upon the social interactions that arise through engagement with the process of their development. Foundationally, Lawson constructs this ontology from the Transformational Model of Social Activity which states that structure is required for, but always pre-exists, activity and is subsequently transformed rather than created. He is able to 
demonstrate that this same transformational dependency exists between the technologist and developing technology.

It is hence clear that within the context of technology, transformation has and can be conceptualised in a range of ways and, moreover, that these are generally tethered in some way to materials. However, despite its evidently principal significance in the thinking about the nature of technology, it is argued herein that 'transformation', as a construct, remains definitively underplayed within the curricular documentation and implementation of technology subjects. In the Broad General Education section of Scotland's new Curriculum for Excellence, transformation can perhaps be inferred at points but the term 'transformation' is not explicitly mentioned. The closest incarnation is that of transfer and is discussed as part of an outcome that relate to different forms of energy. It is in place of a stronger transformative dimension that oversimplified perceptions of technology education as 'woodwork' and 'applied science' appear still to take hold and prevail. Such perceptions are incomplete and insufficient for the forging of a more valid curricular identity. Though they may well legitimately refer to some sub-sets of technological activity, a more prominent transformative paradigm could enable such elements to be proportionately situated within a considerably more representative and comprehensive account. This paper hence proposes a transformative epistemology for technology education based not upon the aforementioned conceptualisations of transformation, but rather upon the idea of the transformation of ontological states of a technological solution. In the same way that the seeking of proof, and the process of interpretation constitute respective epistemic sources in the fields of mathematics and science, the transformation of ontological states is argued herein as a core epistemic source for children developing technological capabilities in classrooms. 


\section{A TRANSFORMATIVE EPISTEMOLOGY OF TECHNOLOGY EDUCATION}

Broadly reflective of Frey's distinction between technology as process and as object, the proposed thesis of a transformative epistemology rests upon two tenets. The first of these is that the technological knowledge and capability of the individual can only be comprehensively developed if the opportunity is given for the development of materials-based technological solutions. This has its basis in the argument set forth by Custer (1995) in which technological knowledge can be defined as "knowledge of accumulated practice." Choosing for pupils to read about technology is, for example, considered insufficient on its own for building authentic technological understanding and capability. The discrete authoring of a section of computer code would, in and of itself, be insufficient in this sense also. The second states that opportunity must also exist for said technological solutions to be ultimately manifest in the form of tangible, physical objects. Here, it is imperative to clarify that this by no means precludes the production of solutions that are wholly conceptual or partly tangible, or other rich and essentials forms of activity in technology classrooms with conceptual, procedural, tacit, social, dispositional or value-based outcomes. But it does assert that the inclusion of opportunities for pupils' ideas to be realised in a physical form, is 'technologically' essential. Norström (2011), in discussing epistemic frameworks of technology in schools, states that the results of technological work can be either physical or abstract, and this is recognised by the author. It is also recognised, however, that retaining focus upon physical outcomes is a necessary definitive constraint for the same reasons as are identified by Feenberg (2003). In a critique of the technology and pragmatism arguments posited by Larry A. Hickman, Feenberg notes that conceptual outcomes, among other things, are regarded as technological solutions in much the same way as bulldozer are. He further argues that the extension of this logic made possible by the bleeding over of definitional boundaries means that even novels and sonnets can end up as technological achievements. In primo aspect, this may appear to constrain the scope of 
technological activity, but analysis of the manner in which this concept is grounded in the context of curricular and school technology suggests this not so. Though the true epistemic source in mathematics was seen to rest on the generation of proofs, pupils in schools do not focus solely upon proofs; nor do pupils within science subjects focus solely on the process of interpreting nature. In these subjects, there are a wide range of activities, processes and spheres of understanding that pupils explore through the course of their learning. Equally, this is regarded by the author to hold true for a transformative epistemology in relation to technology subjects and it is for this reason that attention is given to the role of the artefact.

Critical also to a transformative epistemology, is the argument made by Lawson (2007) that "technical objects simply cannot be understood other than in terms of the various activities involved in their design, production and use." (p.2) This, in many senses, supports the idea of the technical artefact as the embodiment of the design and production activities that have forgone its ultimate and 'completed' state. However, rather than conceptualising this development in terms of design, production and use, it is also possible to consider the artefact itself as an evolving ontological entity. Doing so allows for recognition of its varying temporal existence over the course of learning or development as a series of shifts through largely progressive ontological states. From the perspective of pupil agency, and notwithstanding the fact that unintended uses might mitigate aspects of its inherent 'technological' nature postproduction, the completion of a tangible and functionally sound artefact represents an 'endstate' and is that in which the artefact is, ontologically, most comprehensively defined. Indeed, in ontological terms, it can be recognised in this state as an 'endurant' - a class of entities which are said by Bittner et al (2004) to "exist in full in every instant at which they exist at all." (p.248) By contrast, in its initial or early ontological state, the artefact is comparatively less well defined, less comprehensive, mutable and likely to be partly or largely conceptual in nature. Here, it can be generally understood as a 'perdurant'; entities that "unfold themselves 
over time in successive temporal parts or stages.” (p.248) (Brittner et al, 2004) Collectively, these establish a form of ontological pathway into an artefacts more static and defined existence echoing aspects of Simondon's 'concretisation' (Lefebvre, 2011). In this sense, transformation as an epistemic source refers to the transformation of a tangible technological outcome form a conceptual perdurant ontological state into a tangible endurant ontological state. Transformation, for example, does not refer directly to the alteration or re-configuration of materials as in some of the aforementioned discussion, though this will necessarily take place, in varying ways and to differing degrees, as part of navigating this transformative path in a range of contexts. Ultimately, and in the epistemological sense, it is argued that the navigation of this path gives rise to a corpus of characteristically technological knowledge which Herschbach (1995) argues is praxiologically distinct in that is arises from and is embedded within human activity. Not surprisingly this strengthens facets of what Aristotal refers to as techne and phronesis (Dunne, 1993). Rather than an ontological endurant being realised by the mechanistic application of skill, Dunne points to a less stark division with practical wisdom in arguing that techne can be interpreted as involving situationally aware judgement which, in turn, feeds into the development of phronesis. For pupils in classrooms, this will capitalise on range of creative process (Rutland \& Barlex, 2008; Cropley \& Cropley, 2010), the considered application of prior and 'alternative-domain' knowledge (Kilbrink \& Bjurulf, 2013) but also lead to technological capabilities and knowledge which are fostered and shaped by the milieu and context in which the activity is embedded (Rossouw et al, 2010).

WHAT CONSTITUTES ONTOLOGICALLY WELL-DEFINED FOR A TANGIBLE ENDURANT? 
Given the complexity and on-going discussion in this area, it is not the purpose of this paper to generate any form of definitive ontology for technological artefacts. The aim here is to draw upon salient ideas from contemporary thinking that help to substantiate the idea of a transformative pathway in an educational context. What constitutes well-defined for a tangible endurant necessarily rests upon the intrinsic nature of the artefact.

At its simplest level, ontology deals with the nature of existence and one of the primary distinctions of concern here is whether said existence arises naturally or is man-made. Hilpinen (2004), in Kassel (2010), defines an artefact in general philosophical terms as an "entity intentionally made or produced for some reason" but Baker (2004) notes that historically, philosophy has questioned the ontologically proficiency of artificial artefacts when compared to their natural counterparts. The extreme end of this sub-ordinance view decrees that such things do not exist, though Baker argues convincingly, on the principle of primary kinds ${ }^{i}$, that there is no reasonable basis to substantiate this. In accepting, as this author does, that artefacts do exit - and hence possess ontological substance, those that are discerned as being 'technical' are more specifically understood to be "physical bodies that have geometrical, physical, and chemical characteristics, and functional objects that have an intrinsic relation to mental states and intentional actions." (p.119) Houkes \& Meijers (2006). Indeed, this dual nature is something pupils have ownership in shaping in the role of creator as they navigate the transformative path. Rather than being straight forward, however, the functional dimension can give rise to tensions with the notion of an endurant ontological state.

As stated, an ontological endurant exists in full at those points at which it exists at all and, though the physicality of said objects may remain, the successful use of a computer mouse as a paperweight ascribes a function very likely different to that which was intended by the creator. In this sense, the functional dimension of the artefacts ontology is in fact fluid; displaying a horse drawn wagon as part of a museum exhibit arguably swings its function 
towards that of the socio-cultural. Additionally, it is noteworthy that where alternative functions are accidentally or additionally ascribed, they often capitalise more selectively and to a lesser extent on the intrinsic physical capabilities of the artefact - it is, after all, only the weight and shape of the mouse that facilitates its effective use as a paperweight, not the electronics within which instead relate directly to its 'proper' or intended function. There are also contemporary artefacts, such as the smart phone, that transcend this tendency as intentionally multi-functional devices in full acceptance that these need not be fully known or thought of at the point of commercialisation. Such instability in functional description prompted Hookes et al (2002) to argue for 'use plans' rather than 'proper' and 'accidental' functions as a more robust method of detailing the nature of technical artefacts. This, in turns, allows the extent to which the 'computer-mouse-paperweight' has become intrinsically 'less technical' to be questioned, and whether this might detract from its potential status as a tangible endurant. In the context of pupils realising technical solutions in material forms, this centres importance on the nature of a products use.

Just as Hookes et al (2002) tie artefacts to use rather than just function, Crilly (2010), conceptualises artefact roles as either social, aesthetic or technical or a blend thereof. It is argued that a luxury car, whilst capable of executing the technical function of transporting someone between locations, simultaneously performs a social function. Moreover, it remains the case that artefacts fulfilling any one of these roles can be seen as intentionally created to execute some form of function and in possession of physical substance. Given that, to greater or lesser extents, they might also exhibit intrinsic relations to mental states and intentions, the distinction between artefacts and non-technical artefacts remains problematic. Lawson (2007) also examined this theme and, after citing such examples as money and passports as man-made artefacts epitomising social function, synthesises artefact use with the metaphorical conception of technology. Crucially, he argues that in addition to being physically manifest and 
intentionally designed, technical artefacts are distinct because they "extend [human] capability by their positional enrolment in our systems of use" - an assertion that bridges the ontological and metaphorical anchors upon which this paper rests.

In the context of classroom technology education, the extent to which a technical solution has achieved its status as an ontological endurant is necessarily a matter of judgement. Moreover, the discussion surrounding the relationship between function and use may mean that, in one sense, it can never be fully and definitively achieved. The arguments explored do, however, suggest that in moving away from an ill-defined perdurant state, a well-defined technical endurant should strive to embody three conditional and interdependent characteristics. Firstly, it should be intentionally conceptualised to, partly or wholly, enhance human capabilities in some way. Though required, it may not be the only part of the technical solution. Pupils would consider and explore this from the early stages of development at the beginning of the transformative path. Furthermore, this in no way precludes the artefact from performing additional functions during, or even after, its serviceable lifespan. Indeed, with respect to contemporary thinking about the circular economy and beyond cradle-to-cradle development, there is notable advantage in pupils trying to develop artefacts for use after they cross their primary end-of-life boundary (McDonough et al, 2013). Secondly, the technical endurant should be materially developed to a point that is sufficient to reliably realise the required functions. Lastly, the developing endurant must symbiotically shape and be shaped by its intended systems of use as the pupil progresses it further along the transformative path.

\section{A TRANSFORMATIVE EPISTEMOLOGY: LIMITATIONS AND OPPORTUNITIES}

This paper argues that transformation can be considered as a core epistemic source for technology education. The role of materials, the metaphorical paradigm of technology and 
ontological analyses of technical artefacts, uses and states offered critical insights that were newly synthesised in the form of an ontologically transformational path. Here, transformation is considered succinct and epistemically distinct from the proof of mathematics and the scientific interpretation of nature. With respect to pupil praxis, the neighbouring argument was made that navigation of this path — from conceptual perdurant to tangible, technical endurantconstitutes a definitive source of characteristically technological knowledge.

By way of drawing this argument to a close, it is perhaps prudent to note that Jones et al (2013) describe the current curricular position of technology education as "fragile". Indeed, it is hoped that by setting forth these arguments, this paper encourages further analysis, critique and interest in exploring ways of fortifying a more prominent and stable curricular identity as we move forward. In the spirit of such critique, it is important to note that the thesis set forth in this paper offers a provisional point of departure and will itself consolidate more with greater development.

The transformative paradigm deliberately does not dictate any one method of moving from the initial to the final ontological state. Though this is recognised as an area for further theoretical development, it would conceivably accommodate approaches from informal to formal including the design process, arguably recognised as a method central for the domain of technology. Further to this, there is scope to accommodate alterative procedural approaches such as discrete troubleshooting or repair (McCade, 2000) in which the initial ontological state may be far closer to the final.

As previously discussed, the inclusion of the realisation of technical solutions in a physical form is argued as a definitive requirement for the domain, but should not belie or devalue other forms of activities and learning where the outcome is not tangible. Accordingly, efforts to 
explore how far, and in what ways, this transformative paradigm may support other forms of domain-specific activity should not be dismissed.

The established condition that a technical artefact can be distinguished on the basis of having a metaphorical dimension to its ontology has implications for classroom-level task design. Critical consideration of the nature of task briefs may in fact reveal some artefact solutions to embody ontological characteristics that are, for example, aesthetic over technical. Increased cognisance of this at the level of classrooms and task design will allow more control in shaping the form and nature of the knowledge that pupils are likely to construct as a result of navigating the ontological path.

Finally, it is apt to turn back once more to curricular identity. Ultimately, this paper argues that pupils' navigation from an ontologically ill-defined to ontologically well-defined technical object forms a core source of technological knowledge. In doing so, this paper re-positions or epistemically re-frames the concept of transformation as one way of identifying a possible point of domain constancy. Indeed, it is understood that a range of complex factors feed into the subject's current curricular status and identity. However, it is suggested that moves towards predicating the epistemology of technology education upon transformation may offer a new means of bolstering, re-conceptualising and more effectively conveying its role and place as a critical contemporary subject area.

Correspondence: David Morrison-Love, School of Education, University of Glasgow, St. Andrew's Building, 11 Eldon Street, Glasgow, G3 6NH. Email: david.morrisonlove@glasgow.ac.uk.

\section{Acknowledgements}


I am grateful to Prof. Robert Davis and Prof. V. Lally for their helpful comments and suggestions in authoring this paper.

\section{REFERENCES}

Baker, L. R. (2004) The Ontology of Artifacts. Philosophical Explorations, 7.2, pp.99-111

Barlex, D., Pitt, J. (2000) Interaction: The Relationship between Science and Design and Technology in the Secondary School Curriculum (Engineering Council, London, UK)

Bittner, T., Donnelly, M., Smith, B. (2004) Endurants and Perdurants in Directly Depicting Ontologies, Artificial Intelligence Communications, 17.4, pp.247-258

Buldt, B., Löwe, B., Müller, T. (2008) Towards a New Epistemology of Mathematics, Erkenntnis 68.3, pp.309-329, doi: 10.1007/s10670-008-9101-6

Crilly, N. (2010) The Roles that Artefacts Play: Technical, Social and Aesthetic Functions. Design Studies, 31.4, pp.311-344, doi: 10.1016/j.destud.2010.04.002

Cropley, D., Cropley, A. (2010) Recognizing and Fostering Creativity in Technological Design Education, International Journal of Technology and Design Education, 20.3, pp.345-358, doi: $10.1007 / \mathrm{s} 10798-009-9089-5$

Custer, R. L. (1995) Examining the Dimensions of Technology, International Journal of Technology and Design Education, 5.3, pp.219-244

De Vries, M. J. (1996) Technology Education: Beyond the "Technology is Applied Science" Paradigm, Journal of Technology Education, 8.1

De Vries, M. J. (ed) (2012) Positioning Technology Education in the Curriculum (Rotterdam, Springer Science \& Business Media) 
De Vries, M. J. (2008) Gilbert Simondon and the Dual Nature of Technical Artifacts, Techné: Research in Philosophy and Technology, 12.1

Driver, R., Asoko, H., Leach, J., Scott, P., Mortimer, E. (1994) Constructing Scientific Knowledge in the Classroom. Educational Researcher, 23.7, pp.5-12. doi: $10.3102 / 0013189 X 023007005$

Dunne, J. (1993) Back to the Rough Ground: Practical Judgment and the Lure of Technique, (Notre Dame, University of Notre Dame Press)

Edge, D. (1974) Technological Metaphor and Social Control. New Literary History, 6.1, pp.135-147, doi: $10.2307 / 468345$

Feenberg, A. (2003) Pragmatism and Critical Theory of Technology, Techne: Research in philosophy and technology, 7.1, pp.29-33

Fleer, M. (2015) Theorising Technology Education from a Cultural-Historical Perspective: Foundations and Future Imaginings, in: J. P. Williams, A. Jones, C. Buntting, (eds.) The Future of Technology Education (Singapore, Springer)

Frederik, I., Sonneveld, W., de Vries, M. J. (2011) Teaching and Learning the Nature of Technical Artifacts, International Journal of Technology and Design Education, 21.2, pp.277290. doi: $10.1007 / \mathrm{s} 10798-010-9119-3$

Frey, R. E. (1989) A Philosophical Framework for Understanding Technology, Journal of Industrial Teacher Education, 27.1, pp.23-35

Gardner, P. (1994) Representations of the Relationship between Science and Technology in the Curriculum, Studies in Science Education, 24.1, pp.1-28, doi: $10.1080 / 03057269408560037$ 
Glasersfeld, E. Von. (2002) Radical Constructivism in Mathematics Education (New York, Kluwer Academic)

Heidegger, M. (1977) The Question Concerning Technology, and other essays (New York, Harper and Row)

Herschbach, D. R. (1995) Technology as Knowledge: Implications for Instruction, Journal of Technology Education, 7.1

Houkes, W., Meijers, A. (2006) The Ontology of Artefacts: The Hard Problem, Studies in History and Philosophy of Science Part A, 37.1, pp.118-131, doi: 10.1016/j.shpsa.2005.12.013

Houkes, W., Vermaas, P.E., Dorst, K., de Vries, M. J. (2002) Design and Use as Plans: An Action-Theoretical account, Design Studies, 23.3, pp.303-320

Jan, K. B. O., Pedersen, S. A., Hendricks, V. F. (eds) (2009) A Companion to the Philosophy of Technology, (Chichester, UK; Malden, MA, Wiley-Blackwell)

Jones, A., Buntting, C., de Vries, M. J. (2013) The Developing Field of Technology Education: A Review to Look Forward, International Journal of Technology and Design Education, 23.2, pp.191-212, doi: 10.1007/s10798-011-9174-4

Kapp, E. (1877) Grundlinien einer Philosophie der Tecknik (Рипол Классик)

Kilbrink, N., Bjurulf, V. (2013) Transfer of Knowledge in Technical Vocational Education: A Narrative Study in Swedish Upper Secondary School, International Journal of Technology and Design Education, 23.2, pp.519-535, doi: 10.1007/s10798-012-9201-0

Kornwachs, K. (1998) A Formal Theory of Technology? Techné: Research in Philosophy and Technology, 4.1, pp.28-39 
Lawson, C. (2008) An Ontology of Technology, Techné: Research in Philosophy and Technology, 12.1, pp.48-64

Layton, D. (1993) Technology's Challenge to Science Education. Developing Science and Technology Series (Pennsylvania, Taylor \& Francis)

Lefebvre, A. (2011) The Individuation of Nature in Gilbert Simondon's Philosophy and the Problematic Nature of the Technological Object, Techne: Research in Philosophy and Technology, 15.1, pp.1-15

Lewis, T. (2004) A Turn to Engineering: The Continuing Struggle of Technology Education for Legitimization as a School Subject, Journal of Technology Education, 16.1

McCade, J. (1990) Problem Solving: Much More Than Just Design, Journal of Technology Education, 2.1

McCormick, R. (1997) Conceptual and Procedural Knowledge, International Journal of Technology and Design Education, 7.1-2, pp.141-159

McCormick, R. (2006) Technology and Knowledge: Contributions from Learning Theories, in: J. R. Dakers, (ed.) Defining Technological Literacy: Towards an Epistemological Framework (New York, Palgrave Macmillan)

McDonough, W., Braungart, M. (2013) The Upcycle: Beyond Sustainability - Designing for Abundance (New York, North Point Press)

Merrill, G. H. (2010) Realism and Reference Ontologies: Considerations, Reflections and Problems, Applied Ontology, 5.3-4, pp.189-221

Mitcham, C. (1994) Thinking Through Technology: The Path Between Engineering and Philosophy (Chicago, University of Chicago Press) 
Norström, P. (2013) Engineers' Non-Scientific Models in Technology Education, International Journal of Technology and Design Education, 23.2, pp.377-390, doi: 10.1007/s10798-011$9184-2$

Pannabecker, J. R. (1991) Technological Impacts and Determinism in Technology Education: Alternate Metaphors from Social Constructivism, Journal of Technology Education, 3.1

Pedersen, J. (2009) Technological Determinism and the School, The Journal of Educational Enquiry, 2.1, pp.61-65

Pitt, J. C. (2000) Thinking about Technology: Foundations of the Philosophy of Technology (New York, Seven Bridges Press)

Ropohl, G. (1997) Knowledge Types in Technology, International Journal of Technology and Design Education, 7.1-2, pp.65-72

Rossouw, A., Hacker, M., de Vries, M. J. (2011) Concepts and Contexts in Engineering and Technology Education: An International and Interdisciplinary Delphi Study, International Journal of Technology and Design Education, 21.4, pp.409-424, doi: 10.1007/s10798-0109129-1

Rutland, M., Barlex, D. (2008) Perspectives on Pupil Creativity in Design and Technology in the Lower Secondary Curriculum in England, International Journal of Technology and Design Education, 18.2, pp.139-165, doi: 10.1007/s10798-007-9024-6

Sennett, R. (2008) The Craftsman (New Haven \& London, Yale University Press)

Simpson, L. C. (2009) Technological Rationality, in: Jan, K. B. O., Pedersen, S. A., Hendricks, V. F. (eds.) A Companion to the Philosophy of Technology (Chichester, UK; Malden, MA, Wiley-Blackwell) 
Smith, M. R., Marx, L. (1994) Does Technology Drive History? The Dilemma of Technological Determinism (Massachusetts, MIT Press)

Vincenti, W. G. (1990) What Engineers Know and How They Know It: Analytical Studies from Aeronautical History (Baltimore and London, The Johns Hopkins University Press)

Waetjen, W. B. (1993) Technological literacy reconsidered, Journal of Technology Education, 4.2

Williams, J. P. (2011) STEM Education: Proceed with Caution, Design and Technology Education: An International Journal, 16.1, pp.26-35

Williams, J. P., Jones, A., Buntting, C. (2015) The Future of Technology Education (Singapore, Springer)

\footnotetext{
'Baker describes 'primary kinds' as a reductionist concept linked to the constitution view of reality. Baker shows that 'being a coin' is a primary kind property as opposed to 'being an item in a pocket', which is not. An objects primary kind is that which it most fundamentally comprised and which cannot be lost while the object still exists.
} 